\title{
Inhibition of osteopontin overcomes acquired resistance to afatinib in EGFR-mutant non-small-cell lung cancer
}

\author{
Hongye Zhang ${ }^{1}$, Ruiyu Wang ${ }^{1}$, Mingxia Wang ${ }^{1}$, Judong Luo ${ }^{2}$, Changmin Liu ${ }^{3}$ \\ ${ }^{1}$ Department of Oncology, Linyi Central Hospital, Yishui 276400, China; ${ }^{2}$ Department of Radiotherapy, The Affiliated Changzhou No. 2 People's \\ Hospital of Nanjing Medical University, Changzhou 213000, China; ${ }^{3}$ Department of Oncology, Binzhou Medical University Hospital, Binzhou \\ 256603, China \\ Contributions: (I) Conception and design: C Liu, H Zhang; (II) Administrative support: R Wang; (III) Provision of study materials or patients: M \\ Wang; (IV) Collection and assembly of data: J Luo; (V) Data analysis and interpretation: H Zhang; (VI) Manuscript writing: All authors; (VII) Final \\ approval of manuscript: All authors. \\ Correspondence to: Judong Luo. Department of Radiotherapy, The Affiliated Changzhou No. 2 People's Hospital of Nanjing Medical University, \\ Changzhou 213000, China. Email: judongluo@163.com; Changmin Liu. Department of Oncology, Binzhou Medical University Hospital, Binzhou \\ 256603, China. Email: byfylcm@126.com.
}

\begin{abstract}
Background: We aimed to explore a novel therapeutic strategy to conquer acquired resistance to second generation EGFR-TKI afatinib in EGFR-mutant NSCLC.

Methods: Firstly, we established afatinib-resistant cell lines using increasing concentrations of afatinib. Secondly, we over-expressed or silenced the expression of osteopontin (OPN) using in-vitro transfection. Further, western blot analysis was used to detect the expressions of OPN and epithelial-mesenchymal transition (EMT) biomarkers. Finally, cell proliferation was evaluated by MTT assay.

Results: Afatinib ( $\leq 5.0 \mu \mathrm{mol} / \mathrm{L})$-resistant H1650 (H1650-AR) and H1975 (H1975-AR) cells were successfully established, and grew faster compared with both parental cells at the same time interval. Western blot analysis revealed that afatinib significantly promoted the expressions of OPN and EMT biomarkers in H1975-AR and H1650-AR cells. Gain and loss assays validated that OPN over-expression promoted acquired resistance to afatinib, and induced the expressions of EMT biomarkers in H1650-AR and H1975AR cells. Conversely, silencing of OPN not only significantly sensitized resistant cells to afatinib, but also suppressed EMT progression in H1650-AR and H1975-AR cells.
\end{abstract}

Conclusions: These results demonstrated that OPN was required for acquired resistance of EGFRmutant NSCLC cells to afatinib.

Keywords: Afatinib; osteopontin (OPN); epithelial-mesenchymal transition (EMT); NSCLC

Submitted Sep 12, 2019. Accepted for publication Nov 22, 2019.

doi: $10.21037 /$ tcr.2019.12.49

View this article at: http://dx.doi.org/10.21037/tcr.2019.12.49

\section{Introduction}

Lung cancer is the most common cause of cancer-related deaths worldwide, and NSCLC accounts for nearly $80 \%$ of lung cancer cases. The patients suffering from advanced NSCLC often had a poor 5-year overall survival rate (1). Afatinib is a second-generation of EGFR-TKIs, and has a significant clinical benefit for NSCLC patients with EGFRactivating mutations $(2,3)$. Despite the initial response, patients almost invariably become resistant to afatinib gradually, and relapse after several months (4,5). Recently, it has been reported that secondary (T790M) and tertiary kinase domain mutations (C797S) prevent TKI to inhibit the kinase activity $(6,7)$. Based on these mutations, a third generation of EGFR TKIs were designed and synthesized, and effectively block EGFR kinase activity. In spite of the significant initial clinical efficacy, resistance to EGRTKIs also inevitably occurs and leads to failed treatment finally. Therefore, it is essential to explore more molecular 
mechanisms to overcome acquired resistance to afatinib and improve therapeutic efficacy in EGFR-mutant patients.

Osteopontin $(\mathrm{OPN})$, an arginine-glycine-aspartatecontaining adhesive glycoprotein, expressed highly in various types of cancers, such as squamous cell cancer of the esophagus $(8,9)$. OPN was also involved into resistance to anti-cancer therapy in different cancers, including breast cancer (10), colon cancer (11), hepatocellular carcinoma (12), and oral cancer (13). However, the involvement of OPN in acquired resistance to afatinib is still not clear till now.

In this work, we investigated the biological role of OPN in acquired resistance of EGFR-mutant NSCLC cells to afatinib. We over-expressed or silenced the expression of OPN protein through transfection. Further, western blot analysis was used to detect the expressions of OPN and epithelial-mesenchymal transition (EMT) biomarkers. Finally, cell proliferation assays were performed to evaluate the effect of OPN on afatinib-resistant cells. Our results indicated that OPN is a novel target for EGFR-mutant NSCLC patients with acquired resistance to afatinib.

\section{Methods}

\section{Cell culture}

EGFR-mutant NSCLC cell lines H1975 and H1650 were cultured in RPMI-1640 (CORNING) medium containing $10 \%$ fetal bovine serum (Capricon), $100 \mathrm{IU} /$ $\mathrm{mL}$ of penicillin and $100 \mathrm{~g} / \mathrm{mL}$ of streptomycin (Beyotime Institute of Biotechnology) in $5 \% \mathrm{CO}_{2}$ at $37^{\circ} \mathrm{C}$.

\section{Transfection}

OPN-specific siRNAs (si-OPN) and negative control siRNA (si-control) were purchased from GenePharma (GenePharma Co., Ltd., Shanghai, China). Cells were transfected with $50 \mathrm{nM}$ siRNAs using Lipofectamine 2000 (Invitrogen; Thermo Fisher Scientific, Inc.) according to the manuscript introduction. Subsequent experiments were performed $48 \mathrm{~h}$ post-transfection. The OPN-expressing lentivirus vector pLOC-OPN and its negative control pLOC-NC were generously provided by Shanghai Jiaotong University (Shanghai China). Cells infected with lentiviruses harboring OPN or negative control were selected by $10 \mu \mathrm{g} / \mathrm{mL}$ blasticidin (Selleck), and finally determined by Western blotting.

\section{Cell viability assay}

Briefly, the medium was removed and a fresh medium containing $0.5 \mathrm{mg} / \mathrm{mL}$ MTT was added to each well. The cells were incubated at $37^{\circ} \mathrm{C}$ for $4 \mathrm{~h}$. And then, the supernatants were removed, $50 \mu \mathrm{L}$ dimethylsulfoxide (DMSO) was added to each well, and samples were incubated for $30 \mathrm{~min}$ at $37^{\circ} \mathrm{C}$ with gentle shaking. Finally, the absorbance was determined using a microplate reader at $490 \mathrm{~nm}$. Cell viability was calculated as the ratio of the absorbance determined in the samples to that of the control group.

\section{Cell-proliferation inbibition assays}

Briefly, cells were resuspended in medium containing $0.5 \%$ FBS in a Prime Surface 96U 96-well plate (Sumitomo Bakelite Co. Ltd., Tokyo, Japan) at $5 \times 10^{3}$ cells/well. After overnight incubation, agents were added to the medium at 2.5-100 $\mu \mathrm{M}$ for afatinib. Cell viability was quantified based on luminescence after the addition of the CellTiter-Glo reagent. All experimental points were set up in 6 wells.

\section{Western blotting}

Cells were seeded at a density of $1 \times 10^{6}$ cells/plate in Prime Surface 60-mm plates (Sumitomo Bakelite Co. Ltd., Tokyo, Japan) and allowed to grow overnight in medium containing $0.5 \%$ FBS before the addition of the drug to the medium. Cells were incubated for various times with various concentrations of drugs, then washed with phosphatebuffered saline (PBS) and lysed in buffer containing $25 \mathrm{mM}$ Tris (pH 8.3), $192 \mathrm{mM}$ glycine, $0.1 \%$ sodium dodecyl sulfate, and $1 \mathrm{mM}$ phenylmethylsulfonyl fluoride. Cell lysates were centrifuged at $15,000 \times \mathrm{g}$ for $10 \mathrm{~min}$ at $4{ }^{\circ} \mathrm{C}$, and the supernatant was collected for subsequent procedures. Western blotting was performed following a standard protocol; samples were resolved by sodium dodecyl sulfate polyacrylamide gel electrophoresis and transferred to nitrocellulose membranes, which were probed with antibodies against OPN, E-cadherin, N-cadherin, Vimentin, and GAPDH (Santa Cruz Biotechnology, Santa Cruz, CA, USA). Antibodies were used at dilutions recommended by manufacturers, and signals were detected using an enhanced chemiluminescence system (GE Healthcare, Pittsburgh, PA, USA). 

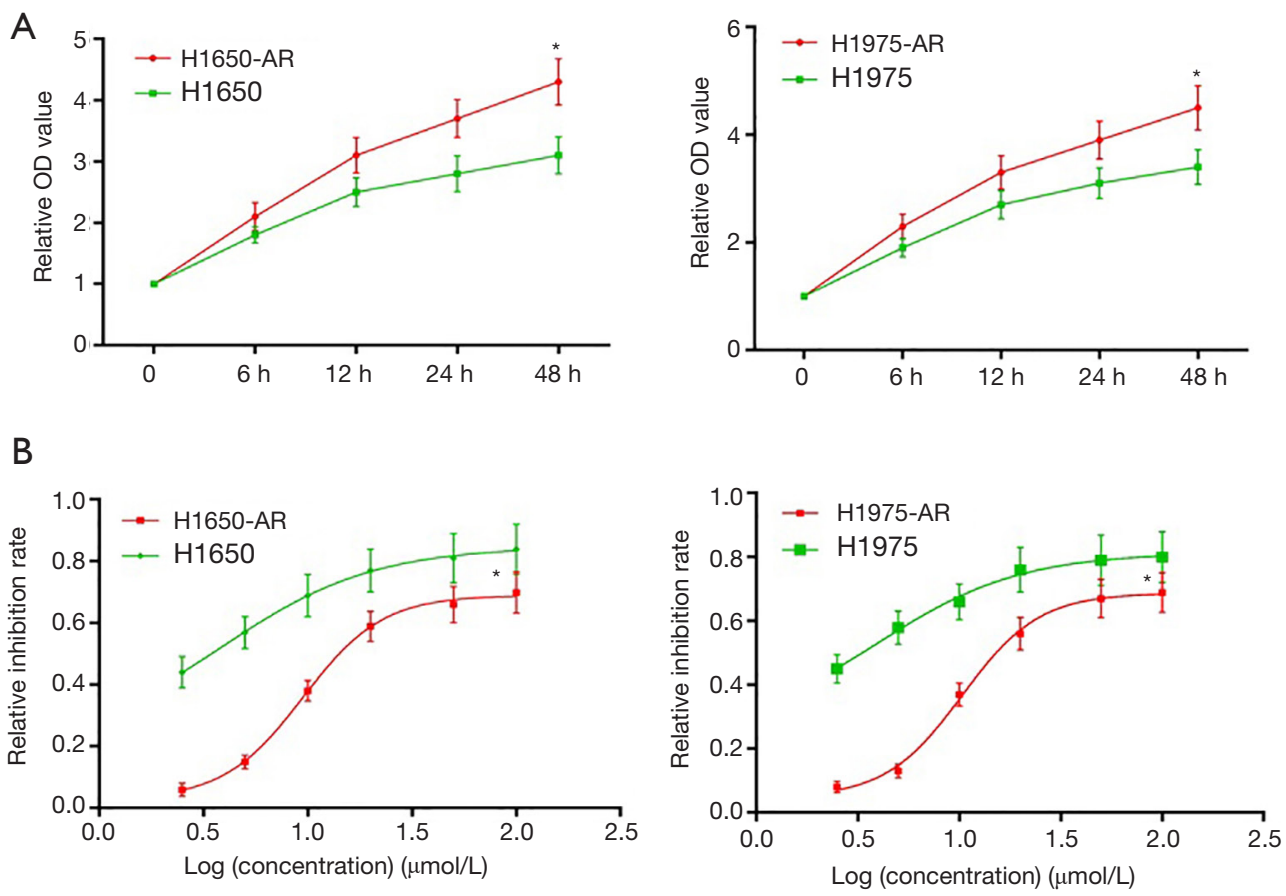

Figure 1 Establishment and identification of afatinib-resistant H1975 and H1650 cell lines. (A) H1975 and H1650 cells were administrated with increasing concentration of afatinib $(0.2$ to $10 \mu \mathrm{mol} / \mathrm{L})$ in complete medium. Following exposure to increasing concentration of afatinib for at least 6 months, live cells that developed acquired resistance to less than $5.0 \mu \mathrm{mol} / \mathrm{L}$ of afatinib were collected. H1650, H1650-AR, H1975 and H1975-AR cells were treated with $5.0 \mu \mathrm{mol} / \mathrm{L}$ of afatinib for indicated times, and then the optical density (OD) value of cell proliferation was determined by MTT assay. (B) H1650, H1650-AR, H1975 and H1975-AR cells were administrated with afatinib (2.5, $5.0,10,20,50,100 \mu \mathrm{mol} / \mathrm{L})$ for $48 \mathrm{~h}$, and then cell proliferation inhibition assay was carried out. Data was represented as mean \pm SD. Each experiment was assayed in triplicate independently. ${ }^{*} \mathrm{P}<0.01$, vs. control.

\section{Statistical analysis}

Graph Pad Prism 5 (Inc; La Jolla, CA, USA) was used for statistical analysis. Values were presented as the mean \pm standard deviation (SD). One-way Analysis of Variance (ANOVA) test was performed to analyze the significance of between-group differences. The least significant difference (LSD) method of multiple comparisons was applied when the probability for ANOVA was statistically significant. Statistical significance was determined at a $\mathrm{P}<0.05$ level.

\section{Results}

\section{Establishment and identification of afatinib-resistant H165O and H1975 cell lines}

To investigate the mechanisms underlying acquired resistance to afatinib in EGFR-mutant NSCLC, we selected H1650 (EGFR mutation: E746-A750del) and H1975 (EGFR mutation: T790M, L858R) cell lines from a series of EGFR-mutant NSCLC cell lines to establish afatinibresistant H1650 and H1975 cells. Firstly, H1650 and H1975 cells were exposed to increasing concentrations of afatinib $(0.2$ to $10 \mu \mathrm{mol} / \mathrm{L})$ in complete medium. Following exposure to increasing concentration of afatinib for at least 6 months, we collected live H1650 and H1975 cells that developed acquired resistance to afatinib $(\leq 5.0 \mu \mathrm{mol} / \mathrm{L})$. Then, we measured cell proliferation using MTT assay. We found that H1650-AR and H1975-AR cells grew faster compared with both parental cells at the same time interval $(\mathrm{P}<0.01$, Figure $1 A)$.

Subsequently, H1650, H1650-AR, H1975 and H1975AR cells were administrated with increasing concentrations of afatinib $(2.5,5.0,10,20,50,100 \mu \mathrm{mol} / \mathrm{L})$ for $48 \mathrm{~h}$. Then cell proliferation inhibition assay was carried out, and the IC50 value of afatinib was determined by Graph Pad Prism 5. As shown in Figure 1B, H1650 and H1975 cells were sensitive to afatinib with low IC50 values of 3.86 and $3.93 \mu \mathrm{mol} / \mathrm{L}$, respectively. By contrast, H1650-AR and 

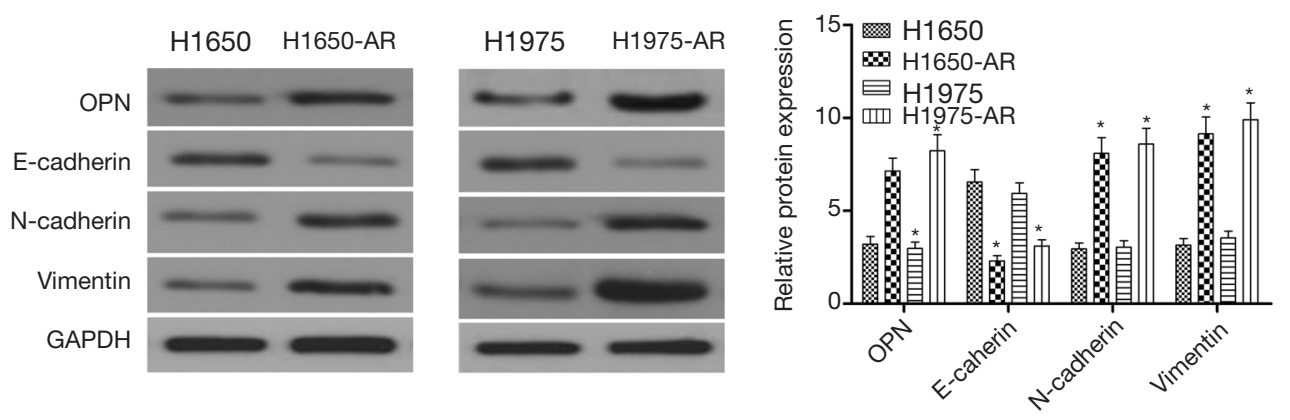

Figure 2 Afatinib induces the expressions of OPN and EMT biomarkers in H1975-AR and H1650-AR cells. H1650, H1650-AR, H1975 and H1975-AR cells were lysed for western blot analysis after treated with $5.0 \mu \mathrm{mol} / \mathrm{L}$ of afatinib for 48 hours. Then the expression levels of OPN, E-cadherin, N-cadherin, and Vimentin proteins were measured through western blot. These blots were cropped with Photoshop CS6. The bands of proteins were measured by densitometry with Quantity One quantitation analysis software package. Data was represented as mean \pm SD. ${ }^{*} \mathrm{P}<0.01$, vs. control. OPN, osteopontin; EMT, epithelial-mesenchymal transition.

H1975-AR cells were resistant to afatinib with significantly high IC50 values of 9.49 and $10.34 \mu \mathrm{mol} / \mathrm{L}$, respectively $(\mathrm{P}<0.01)$. These results validated that we successfully established afatinib-resistant H1650 and H1975 cells.

\section{Afatinib induces the expressions of OPN and EMT biomarkers in H1975-AR and H1650-AR cells.}

To discover the mechanisms of acquired resistance to afatinib, H1650, H1650-AR, H1975 and H1975AR cells were exposed to $5.0 \mu \mathrm{mol} / \mathrm{L}$ of afatinib for $48 \mathrm{~h}$. Western blot analysis was performed and shown in Figure 2. The results illustrated that H1650-AR and H1975AR cells showed an approximately two-fold increase in the expression of OPN protein compared with that in H1650 and $\mathrm{H} 1975$ cells $(\mathrm{P}<0.01)$. Further analysis revealed that afatinib obviously decreased the expression of E-cadherin, but increased the expressions of N-cadherin and Vimentin proteins, indicating $\mathrm{H} 1650-\mathrm{AR}$ and $\mathrm{H} 1975$-AR cells exhibited an EMT phenotype $(\mathrm{P}<0.01$, Figure 2$)$. These results indicated that OPN was significantly up-regulated in afatinib-resistant H1650 and H1975 cells, and might be involved in the mechanisms of acquired resistance to afatinib.

\section{OPN over-expression contributes to acquired resistance to afatinib}

Given the requirement of OPN for EGFR-mutant NSCLC cells, we investigated whether OPN over-expression would be sufficient to cause further resistance to afatinib. Here, we transfected a pLOC-OPN lentivirus vector into H1650-AR and H1975-AR cells to over-express OPN protein. Empty vector was used as a control. Firstly, OPN-expressing lentiviruses indeed increased the expression of OPN protein in H1650-AR and H1975-AR cells $(\mathrm{P}<0.01$; Figure $3 A)$. And then, H1650-AR and H1975-AR with pLOC-OPN lentivirus vector or empty vector were exposed to increasing concentrations of afatinib for $48 \mathrm{~h}$. Finally, the proliferation inhibition rate and IC50 values of afatinib were determined by cell proliferation inhibition assay. Compared with empty vector control (IC50 value: 9.78 and $9.52 \mu \mathrm{mol} / \mathrm{L}$, respectively), over-expression of OPN markedly increased the IC50 values of afatinib (10.99 and $15.12 \mu \mathrm{mol} / \mathrm{L}$, respectively) in H1650-AR and H1975-AR cells $(\mathrm{P}<0.01$, Figure $3 B$ ). These results suggested that OPN overexpression contributed to acquired resistance to afatinib.

\section{OPN over-expression promotes EMT in H1650-AR and H1975-AR cells}

Previous studies identified EMT as a cause of acquired resistance to afatinib in EGFR-mutant NSCLC. EMT renders cancer cells more migratory and invasive, which partially leads to acquired resistance to EGFR-TKIs and correlates with a poor prognosis of NSCLC patients (14). Therefore, we investigated whether OPN can regulate EMT in EGFR-mutant H1650-AR and H1975-AR cell lines using western blot. We identified that H1650-AR and H1975-AR cells with OPN over-expression had 2.1 and 2.3-fold increase in the expressions of $\mathrm{N}$-caherin and Vimentin proteins $(\mathrm{P}<0.01$, Figure 4$)$. However, OPN over- 


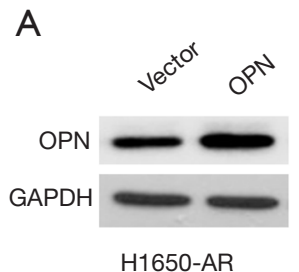

B
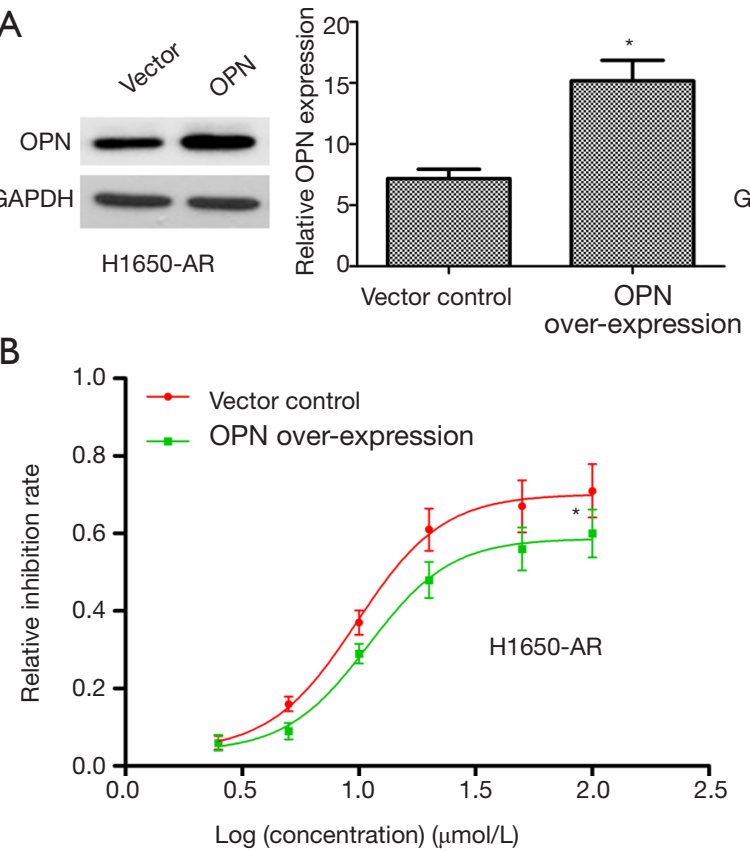
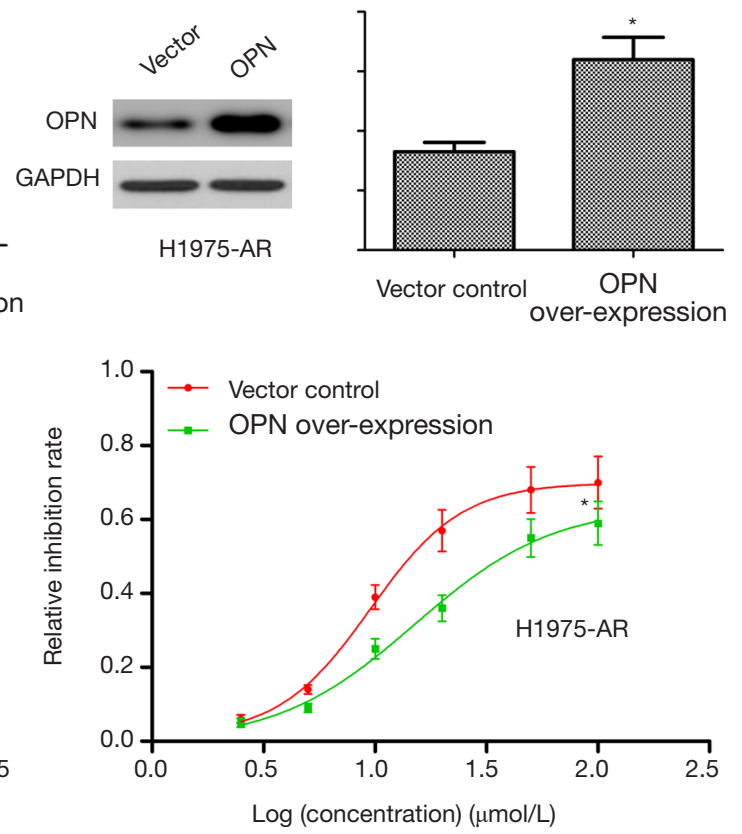

Figure 3 OPN over-expression contributes to acquired resistance to afatinib in H1650-AR and H1975-AR cells. (A) The pLOC-OPN lentivirus vector was used to over-express OPN in H1650-AR and H1975-AR cells. Empty vector was used as a control. The expression level of OPN protein was measured by western blot. (B) H1650-AR and H1975-AR cells with OPN over-expression or empty vector control were administrated with afatinib $(2.5,5.0,10,20,50,100 \mu \mathrm{mol} / \mathrm{L})$ for $48 \mathrm{~h}$; Then cell proliferation inhibition assay was carried out. Each experiment was repeated at least 3 times independently. Data was represented as mean $\pm \mathrm{SD} .{ }^{*} \mathrm{P}<0.01$, vs. control. OPN, osteopontin.

H1650-AR

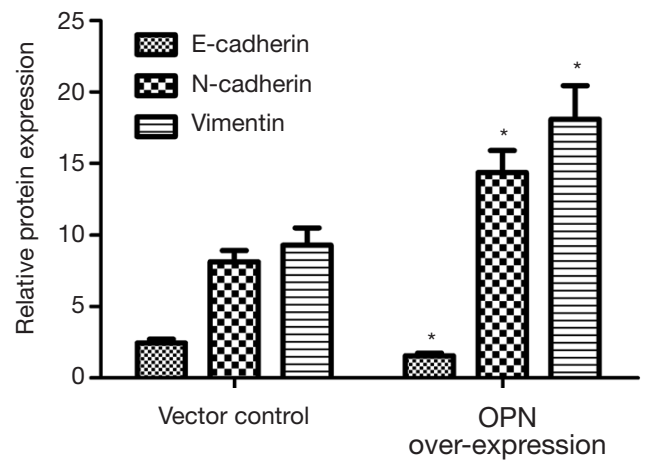

H1975-AR

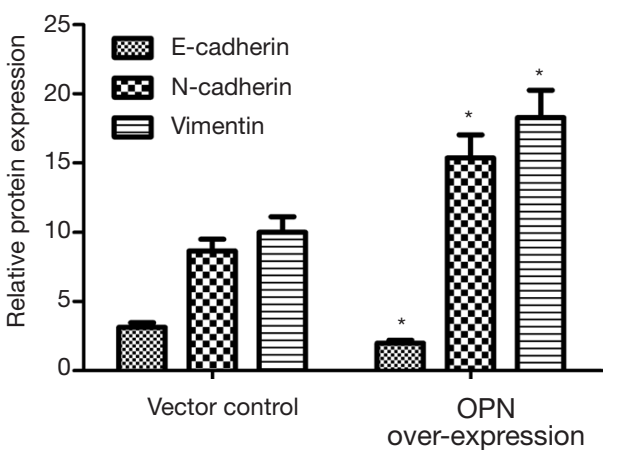

Figure 4 OPN over-expression induces the expressions of EMT biomarkers in H1650-AR and H1975-AR cells. The pLOC-OPN lentivirus vector was used to over-express OPN in H1650-AR and H1975-AR cells. Empty vector was used as a control. The expression levels of E-cadherin, N-cadherin, and Vimentin were measured by western blot. Quantitative analysis was performed by determining the ratio between indicated protein and GAPDH protein levels from three different experiments with densitometry. Each experiment was repeated at least 3 times independently. Data was represented as mean $\pm \mathrm{SD}$. ${ }^{*} \mathrm{P}<0.01$, vs. control. OPN, osteopontin; EMT, epithelial-mesenchymal transition. 
expression in H1650-AR and H1975-AR cells suppressed the expression of E-cadherin protein compared with empty vector control $(\mathrm{P}<0.01$, Figure 4$)$. These results suggested that OPN over-expression promoted EMT progression in H1650-AR and H1975-AR cells.

\section{Silencing of OPN overcomes acquired resistance to afatinib}

Given the significant increase of OPN in H1650-AR and H1975-AR cell lines, we further investigated whether OPN inhibition with the small interfering RNA would be sufficient to overcome acquired resistance to afatinib in both cell lines. We transfected OPN-specific siRNAs or control siRNAs into H1650-AR and H1975-AR cells. Compared with si-control, H1650-AR and H1975-AR cells with si-OPN exhibited an approximately $50 \%$ decrease in the expression of OPN protein $(\mathrm{P}<0.01$, Figure $5 A)$. Following transfection, the proliferation inhibition rate and IC50 values of afatinib were determined by cell proliferation inhibition assay. We found that silencing of OPN in H1650AR and H1975-AR cells decreased the IC50 values of afatinib (6.02 and $4.98 \mu \mathrm{mol} / \mathrm{L}$, respectively) compared with si-control (9.68 and $10.12 \mu \mathrm{mol} / \mathrm{L}$, respectively), indicating that inhibition of OPN overcomes acquired resistance to afatinib via inhibition of cell proliferation $(\mathrm{P}<0.01$, Figure $5 B$ ). In addition, western blot analysis validated that silencing of OPN in H1650-AR and H1975-AR cells treated with afatinib $(5.0 \mu \mathrm{mol} / \mathrm{L})$ significantly decreased the expressions of $\mathrm{N}$-cadherin and Vimentin proteins, but obviously increased the expression of E-cadherin compared with si-control $(\mathrm{P}<0.01$, Figure 5 C). These results indicated that inhibition of OPN overcame acquired resistance to afatinib via inhibition of EMT.

\section{Discussion}

Lung cancer is the most common malignant tumor around the world, in which $80-85 \%$ is NSCLC. The secondgeneration EGFR-TKIs have a greater survival benefit for NSCLC patients especially with EGFR mutations. Compared with the conventional chemotherapy, patients with sensitive EGFR mutations had a better prognosis and sensitivity to EGFR TKIS. Although targeted therapies in NSCLC patients have improved antitumor effects, acquired resistance is still a major barrier to the treatment of NSCLC in clinical practice.

To date, EMT has been demonstrated to be associated with acquired resistance of lung cancer to EGFR TKIs
(15-18), whereas its direct mechanism has not been clearly elucidated in recent years. In previous studies, upregulation of Axl, transforming growth factor- $\beta$ and insulinlike growth factor 1 receptor triggered EMT-mediated acquired resistance to EGFR-TKIs (19-22). In addition, EMT transcription factors, such as SNAI2 and ZEB1, are also responsible for acquired resistance to targeted therapy of EGFR-mutant NSCLC (23-26). However, more molecular mechanisms for targeting EMT or preventing drug resistance need to be investigated.

OPN, as a new cytokine, plays an important role in human body. OPN is associated with pathological processes such as solid tumor, atherosclerotic plaque, sarcoma tissue formation, etc. OPN also plays an important role in tumor metastasis and can be regarded as a marker of tumor metastasis through binding with av $\beta 3$-integrin and CD44 receptor (27). Jin et al. indicated that OPN highly expressed in human NSCLC tissues, and correlated with poor prognosis of NSCLC patients (28). Mechanically, OPN promotes the EMT in several types of cancer cells, including endometrial cancer, prostate cancer, breast cancer and liver cancer (29-31). However, the mechanisms underlying OPN-induced EMT remain poorly understood. The current research on OPN is still at the basic research stage, and there is no specific OPN inhibitor applied in clinical work. In the present study, we selected EGFRmutant $\mathrm{H} 1650$ and $\mathrm{H} 1975$ cells to investigate the role of OPN in acquired resistance to afatinib. Firstly, we successfully established H1650-AR and H1975-AR cells that exhibited an EMT phenotype as characterized by loss of $\mathrm{E}$-cadherin expression and gain of $\mathrm{N}$-cadherin and Vimentin expressions. Afatinib concentration was 0.2 to $10 \mu \mathrm{mol} / \mathrm{L}$, which is fully consistent with the conversion of the usual dose of afatinib in clinical work. We demonstrated that silencing of OPN resulted in proliferation inhibition, and affected EMT progression in H1650-AR and H1975AR cells, while OPN over-expression had an opposite effect, and caused further resistance to afatinib. These results indicated that inhibition of OPN increased sensitivity of H1650-AR and H1975-AR cell lines to afatinib via inhibition of cell proliferation and EMT. OPN can modulate the development of EMT cells, and it has been demonstrated in animal experiments that OPN can promote the metastasis of hepatoma cells (32). In breast cancer, OPN can mediate cancer cells through mitogen-activated protein kinase (MAPK) pathway, the exogenous OPN can promote the proliferation, migration and invasion of endometrial cancer cells EMT can also be promoted by extracellular 

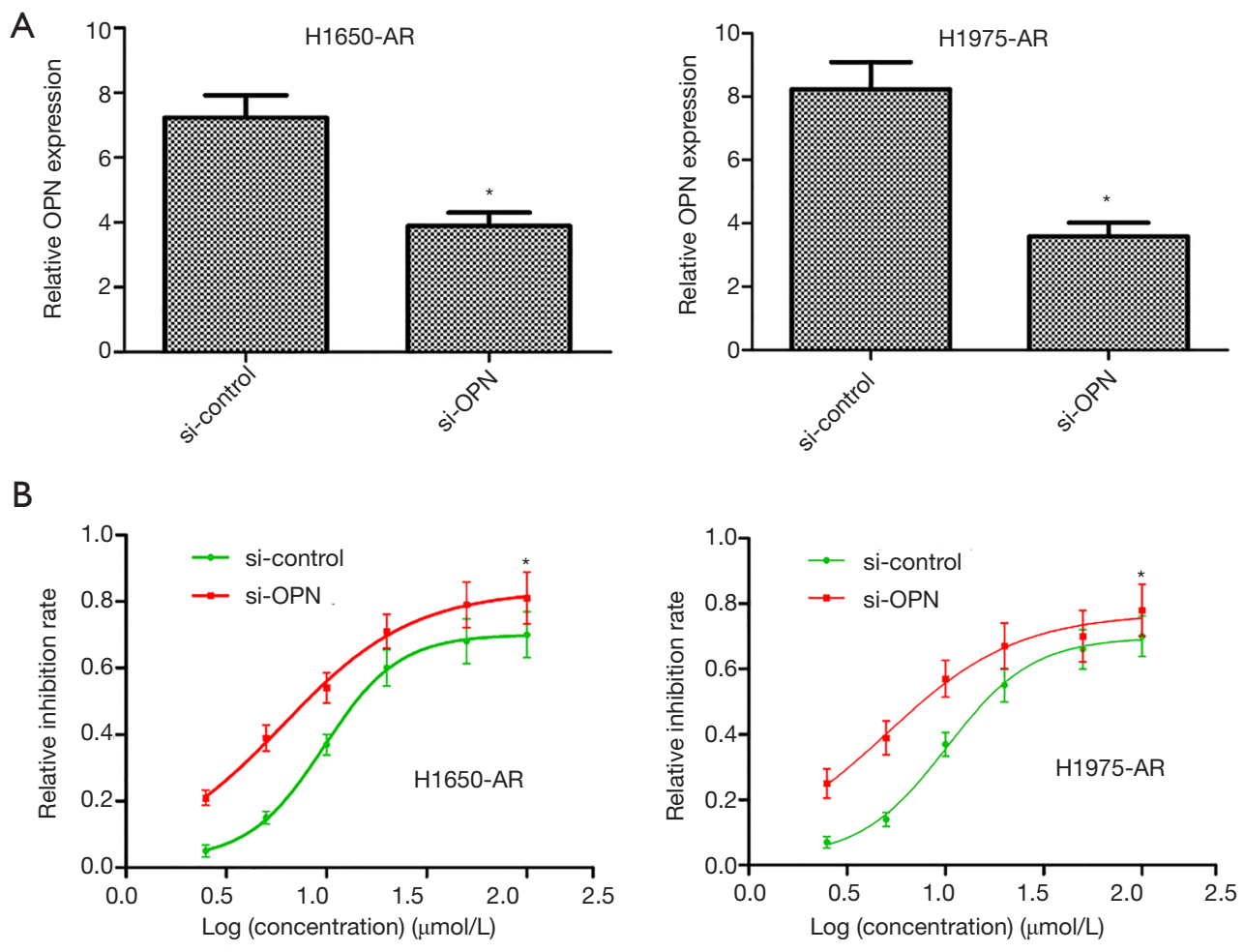

C
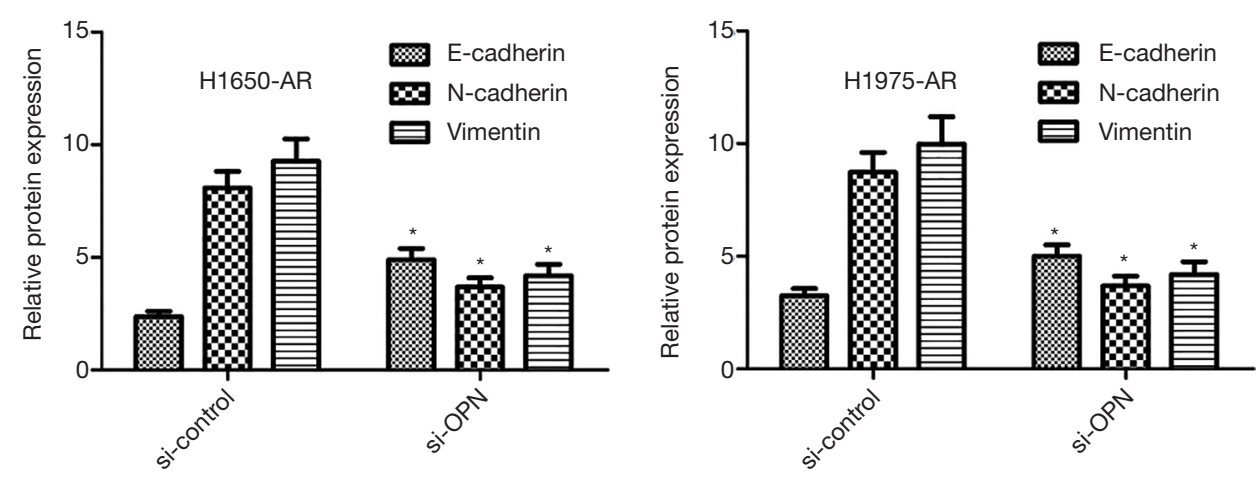

Figure 5 Inhibition of OPN overcomes acquired resistance to afatinib in H1650-AR and H1975-AR cells. (A) Following transfection of OPN-specific siRNAs into H1650-AR and H1975-AR cells, the expression level of OPN protein was measured by western blot. (B) The inhibition rates of cells treated with afatinib were determined by cell proliferation inhibition assay. The IC50 values were calculated through Graph Pad Prism 5. (C) The expression levels of E-cadherin, N-cadherin, and Vimentin were measured by western blot. Quantitative analysis was performed by determining the ratio between indicated protein and GAPDH protein levels from three different experiments with densitometry. Each experiment was repeated at least 3 times independently. Asterisks indicated statistically significant differences. Data was represented as means $\pm \mathrm{SD}$. ${ }^{*} \mathrm{P}<0.01$, vs. control. OPN, osteopontin.

regulated protein kinase 1/2 (ERK1/2) and protein kinase $\mathrm{B}(\mathrm{PKB})$ signal transduction pathway (33). All of those are consistent with our experiment.

In conclusions, our study suggested that OPN was required for acquired resistance of EGFR-mutant NSCLC cell lines to afatinib. We believe that combination of afatinib and OPN inhibitors may be a better therapeutic option for NSCLC patients who developed acquired resistance to afatinib. Whether resistance will occur upon combination treatment remains to be seen in clinical trials. 


\section{Acknowledgments}

Funding: This work is supported by Scientific Projects of Jiangsu Province (BE2018643; BK20191157; BRA2018168), and Scientific Program of Changzhou (CE20195048; ZD201919; CE20185045).

\section{Footnote}

Conflicts of Interest: All authors have completed the ICMJE uniform disclosure form (available at http://dx.doi. org/10.21037/tcr.2019.12.49). The authors have no conflicts of interest to declare.

Ethical Statement: The authors are accountable for all aspects of the work in ensuring that questions related to the accuracy or integrity of any part of the work are appropriately investigated and resolved. The study was approved by the Ethics Committee of the Binzhou Medical University Hospital (No. 2018-024-03).

Open Access Statement: This is an Open Access article distributed in accordance with the Creative Commons Attribution-NonCommercial-NoDerivs 4.0 International License (CC BY-NC-ND 4.0), which permits the noncommercial replication and distribution of the article with the strict proviso that no changes or edits are made and the original work is properly cited (including links to both the formal publication through the relevant DOI and the license). See: https://creativecommons.org/licenses/by-ncnd/4.0/.

\section{References}

1. Chen J, Wang R, Zhang K, et al. Long non-coding RNAs in non-small cell lung cancer as biomarkers and therapeutic targets. J Cell Mol Med 2014;18:2425-36.

2. Forde PM, Ettinger DS. Targeted therapy for non-smallcell lung cancer: past, present and future. Expert Rev Anticancer Ther 2013;13:745-58.

3. Lee CK, Brown C, Gralla RJ, et al. Impact of EGFR inhibitor in non-small cell lung cancer on progression-free and overall survival: a meta-analysis. J Natl Cancer Inst 2013;105:595-605.

4. Roengvoraphoj M, Tsongalis GJ, Dragnev KH, et al. Epidermal growth factor receptor tyrosine kinase inhibitors as initial therapy for non-small cell lung cancer: focus on epidermal growth factor receptor mutation testing and mutation-positive patients. Cancer Treat Rev 2013;39:839-50.

5. Castañóastañ9-50.mal gRolfo C, et al. Epidermal Growth Factor Receptor targeting in non-small cell lung cancer: revisiting different strategies against the same target. Curr Drug Targets 2014;15:1273-83.

6. Yeung K, Carlson JJ. Clinical and economic review of erlotinib in non-small-cell lung cancer. Expert Rev Pharmacoecon Outcomes Res 2012;12:411-23.

7. Cufer T, Knez L. Update on systemic therapy of advanced non-small-cell lung cancer. Expert Rev Anticancer Ther 2014;14:1189-203.

8. Wu IC, Wu MT, Chou SH, et al. Osteopontin expression in squamous cell cancer of the esophagus. World J Surg 2008;32:1989-95.

9. Kita Y, Natsugoe S, Okumura H, et al. Expression of osteopontin in oesophageal squamous cell carcinoma. $\mathrm{Br} \mathrm{J}$ Cancer 2006;95:634-8.

10. Anborgh PH, Caria LB, Chambers AF, et al. Role of plasma osteopontin as a biomarker in locally advanced breast cancer. Am J Transl Res 2015;7:723-32.

11. Ng L, Wan T, Chow A, et al. Osteopontin Overexpression Induced Tumor Progression and Chemoresistance to Oxaliplatin through Induction of Stem-Like Properties in Human Colorectal Cancer. Stem Cells Int 2015;2015:247892.

12. Liu G, Fan X, Tang M, et al. Osteopontin induces autophagy to promote chemo-resistance in human hepatocellular carcinoma cells. Cancer Lett 2016;383:171-82.

13. Luo SD, Chen YJ, Liu CT, et al. Osteopontin Involves Cisplatin Resistance and Poor Prognosis in Oral Squamous Cell Carcinoma. Biomed Res Int 2015;2015:508587.

14. Poh ME, Liam CK, Rajadurai P, et al. Epithelial-tomesenchymal transition (EMT) causing acquired resistance to afatinib in a patient with epidermal growth factor receptor (EGFR)-mutant lung adenocarcinoma. J Thorac Dis 2018;10:E560-3.

15. Sequist LV, Waltman BA, Dias-Santagata D, et al. Genotypic and histological evolution of lung cancers acquiring resistance to EGFR inhibitors. Sci Transl Med 2011;3:75ra26.

16. Byers LA, Diao L, Wang J, et al. An epithelialmesenchymal transition gene signature predicts resistance to EGFR and PI3K inhibitors and identifies Axl as a therapeutic target for overcoming EGFR inhibitor resistance. Clin Cancer Res 2013;19:279-90.

17. Suda K, Tomizawa K, Fujii M, et al. Epithelial to 
mesenchymal transition in an epidermal growth factor receptor-mutant lung cancer cell line with acquired resistance to erlotinib. J Thorac Oncol 2011;6:1152-61.

18. Witta SE, Gemmill RM, Hirsch FR, et al. Restoring E-cadherin expression increases sensitivity to epidermal growth factor receptor inhibitors in lung cancer cell lines. Cancer Res 2006;66:944-50.

19. Zhang Z, Lee JC, Lin L, et al. Activation of the AXL kinase causes resistance to EGFR-targeted therapy in lung cancer. Nat Genet 2012;44:852-60.

20. Izumchenko E, Chang X, Michailidi C, et al. The TGFl. The 0-MIG6 pathway orchestrates the EMT-associated kinase switch that induces resistance to EGFR inhibitors. Cancer Res 2014;74:3995-4005.

21. Jakobsen KR, Demuth C, Sorensen BS, et al. The role of epithelial to mesenchymal transition in resistance to epidermal growth factor receptor tyrosine kinase inhibitors in non-small cell lung cancer. Transl Lung Cancer Res 2016;5:172-82.

22. Vazquez-Martin A, CufíufquOliveras-Ferraros C, et al. IGF-1R/epithelial-to-mesenchymal transition (EMT) crosstalk suppresses the erlotinib-sensitizing effect of EGFR exon 19 deletion mutations. Sci Rep 2013;3:2560.

23. Yochum ZA, Socinski MA, Burns TF. Paradoxical functions of ZEB1 in EGFR-mutant lung cancer: tumor suppressor and driver of therapeutic resistance. J Thorac Dis 2016;8:E1528-31.

24. Yoshida T, Song L, Bai Y, et al. ZEB1 mediates acquired resistance to the epidermal growth factor receptor-tyrosine kinase inhibitors in non-small cell lung cancer. PLoS ONE 2016;11:e0147344.

25. Zhang T, Guo L, Creighton CJ, et al. A genetic cell

Cite this article as: Zhang H, Wang R, Wang M, Luo J, Liu C. Inhibition of osteopontin overcomes acquired resistance to afatinib in EGFR-mutant non-small-cell lung cancer. Transl Cancer Res 2020;9(2):754-762. doi: 10.21037/tcr.2019.12.49 context-dependent role for ZEB1 in lung cancer. Nat Commun 2016;7:12231.

26. Chang TH, Tsai MF, Su KY, et al. Slug confers resistance to the epidermal growth factor receptor tyrosine kinase inhibitor. Am J Respir Crit Care Med 2011;183:1071-9.

27. Rittling SR, Chambers AF. Role of osteopontin in tumour progression. Br J Cancer 2004;90:1877-81.

28. Jin Y, Tong DY, Chen JN, et al. Overexpression of osteopontin, sepidermal growth factor receptprognostically important clinicopathologic variables in non-small cell lung cancer. PLoS One 2012;7:e48575.

29. Li Y, Xie Y, Cui D, et al. Osteopontin promotes invasion, migration and epithelial-mesenchymal transition of human endometrial carcinoma cell HEC-1A through AKT and ERK1/2 signaling. Cell Physiol Biochem 2015;37:1503-12.

30. Nakamura KD, Tilli TM, Wanderley JL, et al. Osteopontin splice variants expression is involved on docetaxel resistance in PC3 prostate cancer cells. Tumour Biol 2016;37:2655-63.

31. Li NY, Weber CE, Mi Z, et al. Osteopontin up-regulates critical epithelial-mesenchymal transition transcription factors to induce an aggressive breast cancer phenotype. J Am Coll Surg 2013;217:17-26.

32. Dong Q, Zhu X, Dai C, et al. Osteopontin promotes epithelial mesenchymaltransition of hepatocellular carcinoma through regulating vimentin. Oncotarget 2016,7:12997-3012.

33. Yang M, Ma B, Shao H, et al. Macrophage phenotypic subtypes diametrically regulate epithelial mesenchymal plasticity in breast cancer cells. BMC Cancer 2016,16:419-32. 